\title{
Iron in typical and atypical parkinsonism - Mössbauer spectroscopy and MRI studies
}

\author{
R. Kuliński ${ }^{1}$ E. R. Bauminger ${ }^{2}$ A. Friedman ${ }^{3}$. \\ P. Duda ${ }^{4} \cdot$ J. Gałąka-Friedman 4
}

Published online: 18 February 2016

(C) The Author(s) 2016. This article is published with open access at Springerlink.com

\begin{abstract}
Iron may play important role in neurodegeneration. The results of comparative studies of human brain areas (control and pathological) performed by Mössbauer spectroscopy (MS) and magnetic resonance imaging (MRI) techniques are presented. Mössbauer spectroscopy demonstrated a higher concentration of iron in atypical parkinsonism (progressive supranuclear palsy PSP) in the brain areas Substantia Nigra (SN) and Globus Pallidus (GP) involved in this pathological process, compared to control, while the concentration of iron in pathological tissues in typical parkinsonism (Parkinson's disease - PD) did not differ from that in control. These results were compared with the changes in 1/T1 and 1/T2 (T1 and $\mathrm{T} 2$ being the relaxation times determined by MRI). A good linear correlation curve was found between the concentration of iron as determined by MS in different areas of control human brains and between 1/T1 and 1/T2. Whereas the finding in PSP-GP (the brain area involved in PSP) also fitted to such a correlation, this was not so for the correlation between pathological SN - the brain area involved in both diseases - and 1/T2, indicating a dependence of $\mathrm{T} 2$ on other factors than just the concentration of iron.
\end{abstract}

This article is part of the Topical Collection on Proceedings of the International Conference on the Applications of the Mössbauer Effect (ICAME 2015), Hamburg, Germany, 13-18 September 2015

J. Gałązka-Friedman jgfrie@if.pw.edu.pl

1 MRI Lab, Bródno Hospital, Kondratowicza 8, Warsaw, Poland

2 Racah Institute of Physics, Hebrew University, Jerusalem, Israel

3 Department of Neurology, Medical University of Warsaw, Kondratowicza 8, Warsaw, Poland

4 Faculty of Physics, Warsaw University of Technology, Koszykowa 75, Warsaw, Poland 
Keywords Mössbauer spectroscopy $\cdot$ MRI relaxation times $\cdot$ Brain iron · Parkinsonism

\section{Introduction}

Neurodegenerative diseases represent a major and fast growing problem for the human population. The best known by the lay audience are Alzheimer disease and parkinsonism. Neurodegenerative diseases are directly related to the age of the population. The most frequent form of parkinsonism - Parkinson's disease - is present in about $0.2 \%$ of the general population but in the population older than 65 years its frequency is on the level of $2 \%$ [1]. The diagnosis of PD is mostly based on the clinical symptoms of slowness of movements, muscular rigidity and rest tremor. It has to be stressed, however, that besides the typical parkinsonism of PD, neurologists recognize other forms of parkinsonism, which differ from PD by some additional symptoms and different localization of neurodegeneration in the brain. The motor symptoms of PD are caused by the progressive destruction of nervous cells in a small structure of about $0.5 \mathrm{~g}$ mass located bilaterally deep in the brain stem - substantia nigra (SN). In atypical parkinsonism the process affects not only SN but also other structures like globus pallidus (GP). One of these atypical parkinsonisms is progressive supranuclear palsy (PSP). Symptoms of Alzheimer disease are related to the destruction of the hippocampal cortex.

The cause of neurodegenerations remains unknown despite intensive studies all over the world. One of the mechanisms of the death of nervous cells may be related to the so called oxidative stress, in which iron plays an important role [2]. According to this concept, the oxidative stress is mediated by the Fenton reaction:

$$
\mathrm{Fe}^{2+}+\mathrm{H}_{2} \mathrm{O}_{2} \rightarrow \mathrm{Fe}^{3+}+\mathrm{OH}^{\cdot}+\mathrm{OH}^{-},
$$

in which free radicals $\mathrm{OH}^{\circ}$ are generated.

It is important to emphasize that both $\mathrm{SN}$ and GP contain relatively high amounts of iron, being of about $200 \mathrm{ng} / \mathrm{mg}$ fresh tissue. Iron concentration in the hippocampal cortex is much lower, being on the level of $50 \mathrm{ng} / \mathrm{mg}$ fresh tissue [3].

In the past several studies were published showing a significant increase of the concentration of iron in SN in PD compared to control. On the other hand other studies, including our own, did not show any difference in the concentration of total iron between parkinsonian and control SN. The history and controversies related to iron studies in PD were discussed in a review paper [4].

According to our Mössbauer spectroscopy studies, performed at the Racah Institute of Physics at the Hebrew University in Jerusalem, the ratio of iron concentration in PD-SN vs. control $\mathrm{SN}$ is $1.00 \pm 0.13$. These studies did however demonstrate a significantly higher concentration of iron both in SN and GP in atypical parkinsonism PSP compared to control, with the ratio being $1.60 \pm 0.23$ for $\mathrm{SN}$ and $1.40 \pm 0.20$ for GP [5]. A higher concentration of iron in SN and GP in PSP compared to control was also found by others [6].

The aim of our present study is to find the correlation of the results obtained by Mössbauer spectroscopy with the results obtained with magnetic resonance imaging (MRI) for the longitudinal relaxation times T1 and transverse relaxation times T2 from SN and GP in patients with typical PD, PSP and control subjects. 


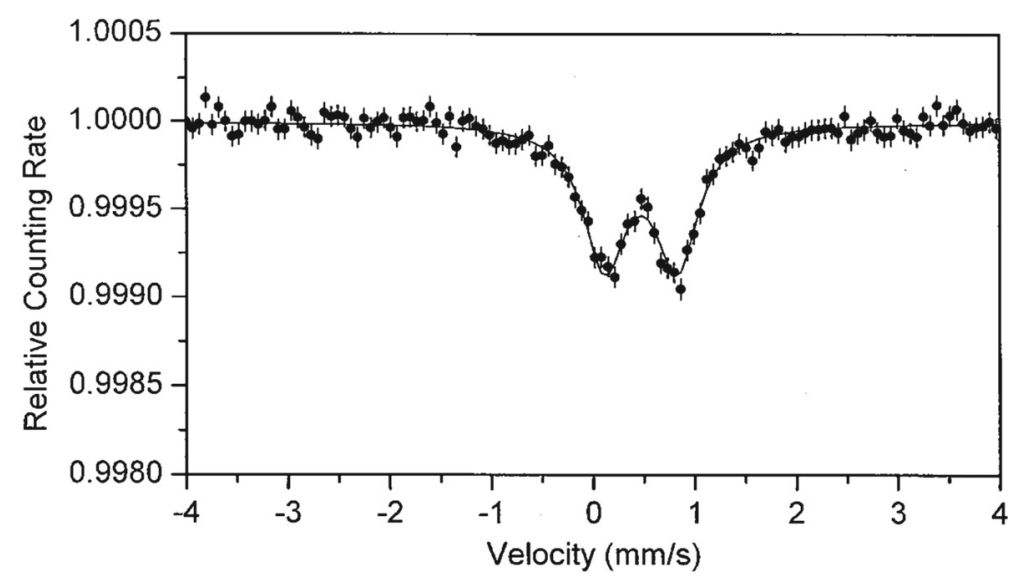

Fig. 1 Mössbauer spectrum of substantia nigra (SN) from atypical parkinsonism (PSP) obtained at $90 \mathrm{~K}$. The weight of the sample was $127 \mathrm{mg}$. The concentration of iron calculated from the spectral area was 375 ng/mg SN tissue

\section{Material and methods}

\subsection{Mössbauer spectroscopy}

Measurements of parkinsonian and control brain samples were performed at the Racah Institute of Physics in Jerusalem between 1990-2010. Control samples were obtained at autopsies from patients who died without any clinical or pathological symptoms of a neurodegenerative disease and pathological samples were obtained from patients who died with clinical and neuropathological symptoms of either PD or PSP. All autopsies were performed within 24 hours after death of the subjects and the brains were kept in $-80^{\circ} \mathrm{C}$ until assayed. 29 control SN, 12 control GP and 10 control hippocampal cortex samples were compared with 17 PD samples of SN, with 10 PSP samples of SN and 10 PSP samples of GP.

The amount of iron in all samples was determined from the overall spectral area. The calibration of the absolute amount of iron versus spectral area was performed by a series of measurements on samples of ferritin, which had a known content of iron [7].

Mössbauer spectra of ${ }^{57} \mathrm{Fe}$ were obtained with a conventional Mössbauer spectrometer at $90 \mathrm{~K}$. A $100 \mathrm{mCi}{ }^{57} \mathrm{Co}$-in-rhodium source, giving a narrow unsplit emission line, was used. The $14.4 \mathrm{keV}$ gamma rays were detected using a Harwell proportional counter with an iron free mylar window. The velocity scale was calibrated using an iron-foil absorber at room temperature. Samples were measured for at least 48 hours and at least 40 million counts per channel ( 256 channels) were obtained.

The experimental Mössbauer spectra were computer fitted with Lorentzian lines.

\subsection{Magnetic resonance imaging}

46 PD patients, 10 PSP and 18 control subjects were assessed with 1.5 T MRI. The clinical diagnosis was made according to generally accepted criteria [8]. 


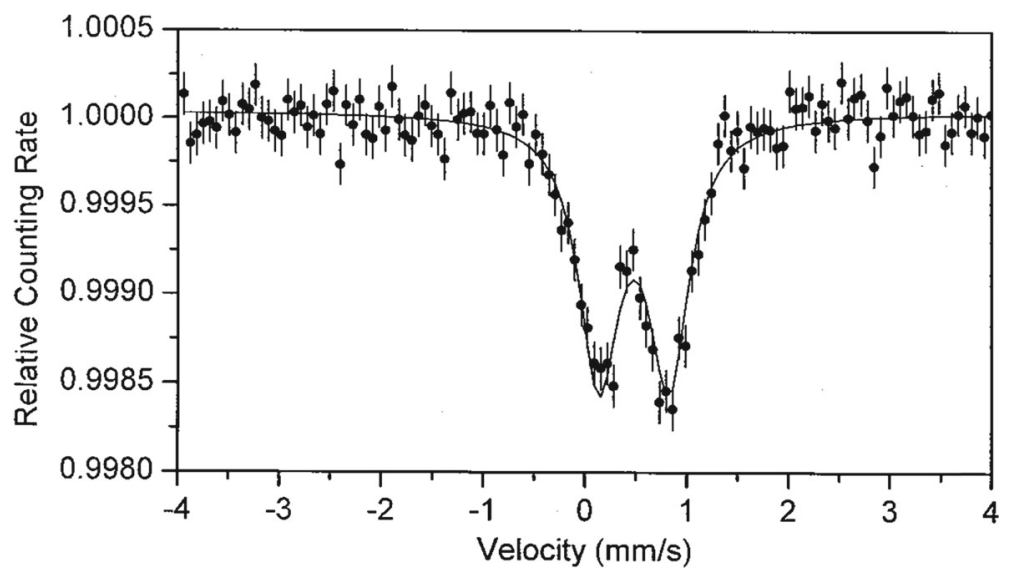

Fig. 2 Mössbauer spectrum of globus pallidus (GP) from atypical parkinsonism (PSP) obtained at $90 \mathrm{~K}$. The weight of the sample was $275 \mathrm{mg}$. The concentration of iron calculated from the spectral area was 457 ng/mg GP tissue

The measurements of T1 and T2 were performed in Brodno Hospital in Warsaw with the use of General Electric 1,5T Sigma Exite MRI with a head coil using pulse methods. Inversion Recovery (IR) pulse sequence was used to measure $\mathrm{T} 1$ (TI=100, 200, 500, 800, 1600, $2400 \mathrm{~ms}$; TR=10000 ms) and Fast Spin Echo (FSE) pulse sequence was used to measure $\mathrm{T} 2(\mathrm{TE}=15,30,45,60 \mathrm{~ms} ; \mathrm{TR}=3000 \mathrm{~ms})$.

\section{Results}

The Mössbauer spectra obtained at $90 \mathrm{~K}$ for all control and pathological samples showed well resolved doublets. For all samples the values of Mössbauer parameters were equal within the errors, with values of IS $=0.46 \pm 0.02$ and $\mathrm{QS}=0.70 \pm 0.04 \mathrm{~mm} / \mathrm{s}$, which are typical for ferritin like iron. The typical value of the linewidth was $0.45 \pm 0.05 \mathrm{~mm} / \mathrm{s}$.

The Mössbauer spectrum of SN from PSP is shown in Fig. 1, and the Mössbauer spectrum of GP PSP is shown in Fig. 2. The results of the assessment of the concentration of iron in brain samples and T1 and T2 relaxation times obtained from the same structures in living subjects are shown in Table 1. The correlation between the concentrations of iron and MRI results is presented in Figs. 3 and 4. Figure 3 shows the dependence of 1/T1 (R1) on the concentration of iron, Fig. 4 shows the dependence of 1/T2 (R2) on the concentration of iron for all samples. Reciprocals R1 and R2 were plotted because they are additive with respect to different relaxation mechanisms [9]. As seen in Fig. 3 there is a linear dependence of R1 on the concentration of iron for all samples measured, with the coefficient of correlation for this straight line being 0.945. On the plot of R2 vs. concentration of iron (Fig. 4) only data from control Hip, SN and GP, and from PSP GP follow a linear dependence with the coefficient of correlation being 0.983. As seen in the figure, the results for SN both in PSP and PD divert from the linear dependence and if these points would be taken into account the coefficient of correlation for a linear plot would be only 0.569 (Fig. 5) This indicates strongly that the correlation between the concentration of iron and MRI results are different for pathological tissues of SN. 
Table 1 The concentration of iron in brain samples and T1 and T2 relaxation times obtained from the same structures in living subjects

\begin{tabular}{|c|c|c|c|}
\hline Patients & $\begin{array}{l}\text { MRI-T1 (ms) } \\
(\mathrm{n}=\text { number of subjects) }\end{array}$ & $\begin{array}{l}\text { MS - iron concentration } \\
\text { (ng/mg wet tissue) } \\
\text { ( } \mathrm{n}=\text { number of samples) }\end{array}$ & $\begin{array}{l}\text { MRI - T2 (ms) } \\
(\mathrm{n}=\text { number of subjects })\end{array}$ \\
\hline & $\mathrm{SN}$ & & \\
\hline \multirow[t]{2}{*}{ Control } & $708 \pm 22$ & $177 \pm 14$ & $52 \pm 1$ \\
\hline & $(\mathrm{n}=18)$ & $(\mathrm{n}=29)$ & $(\mathrm{n}=18)$ \\
\hline \multirow[t]{2}{*}{ PD } & $730 \pm 12$ & $177 \pm 18$ & $47 \pm 1$ \\
\hline & $(n=42)$ & $(\mathrm{n}=17)$ & $(n=46)$ \\
\hline \multirow[t]{3}{*}{ PSP } & $589 \pm 5$ & $301 \pm 26$ & $55 \pm 2$ \\
\hline & $(n=10)$ & $(n=10)$ & $(n=10)$ \\
\hline & GP & & \\
\hline \multirow[t]{2}{*}{ Control } & $681 \pm 8$ & $182 \pm 22$ & $53 \pm 1$ \\
\hline & $(\mathrm{n}=18)$ & $(\mathrm{n}=12)$ & $(n=18)$ \\
\hline \multirow[t]{2}{*}{ PD } & $675 \pm 9$ & - & $49 \pm 1$ \\
\hline & $(\mathrm{n}=42)$ & & $(n=42)$ \\
\hline \multirow[t]{3}{*}{ PSP } & $652 \pm 9$ & $257 \pm 19$ & $46 \pm 2$ \\
\hline & $(\mathrm{n}=10)$ & $(\mathrm{n}=10)$ & $(n=10)$ \\
\hline & Hip & & \\
\hline \multirow[t]{2}{*}{ Control } & $798 \pm 22$ & $45 \pm 10$ & $65 \pm 1$ \\
\hline & $(\mathrm{n}=18)$ & $(\mathrm{n}=10)$ & $(\mathrm{n}=18)$ \\
\hline \multirow[t]{2}{*}{ PD } & $839 \pm 13$ & - & $65 \pm 1$ \\
\hline & $(n=44)$ & & $(n=44)$ \\
\hline \multirow[t]{2}{*}{ PSP } & $708 \pm 7$ & - & $64 \pm 2$ \\
\hline & $(\mathrm{n}=10)$ & & $(\mathrm{n}=10)$ \\
\hline
\end{tabular}

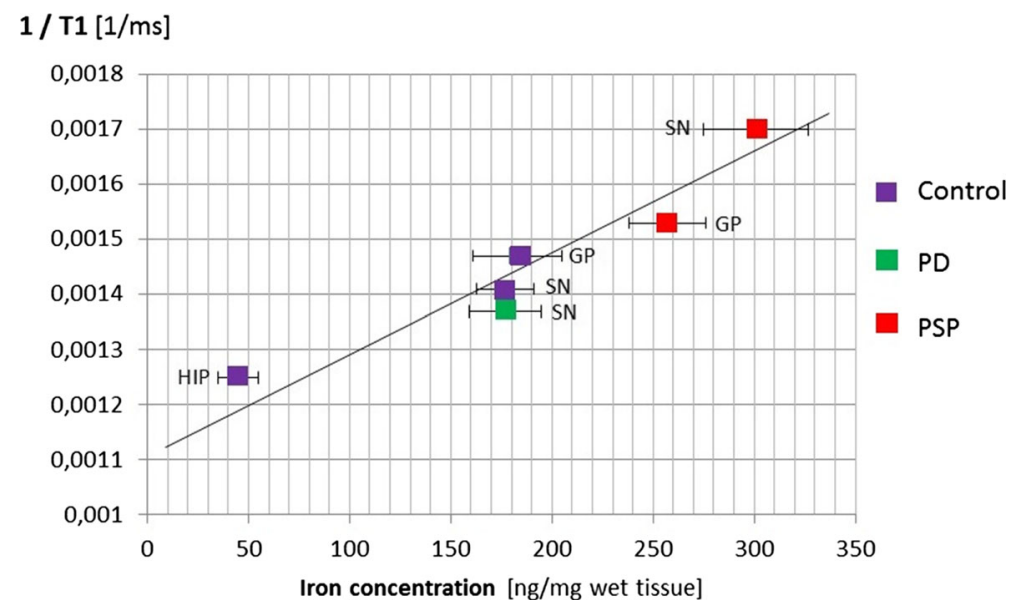

Fig. 3 1/T1 relaxation rate vs. concentration of iron in control (violet), Parkinson's disease (green) and atypical parkinsonism (red). The coefficient of correlation for the straight line shown in the figure is 0.945 


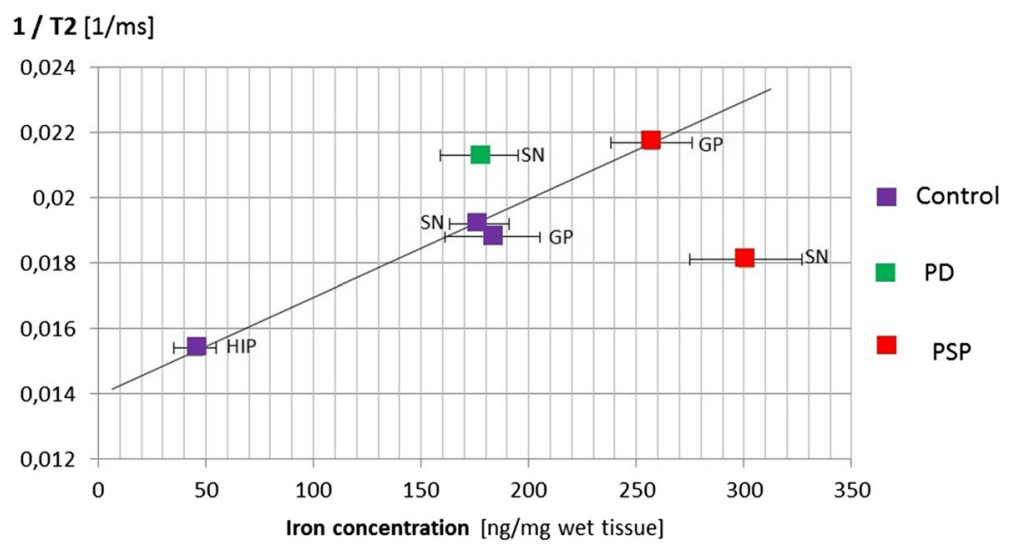

Fig. 4 1/T2 relaxation rate vs. concentration of iron in control (violet), Parkinson's disease (green) and atypical parkinsonism (red). The coefficient of correlation for the straight line shown in the figure, obtained by omitting data for SN from PD and PSP, is 0.983

\section{Discussion}

The impact of iron present in the human body on MRI has been studied since the MRI technique was implemented for medical research. It concerned especially studies of iron in the brain. This issue was discussed in large by Shenck [10] and Haacke et al. [11].

MRI signals are generated mainly by water protons. In pure water values of longitudinal (T1) and transverse (T2) relaxation times do not differ very much from each other. But in human brain $\mathrm{T} 1$ is usually about 10 times longer than $\mathrm{T} 2$. They differ also in areas of the brain characterized by different concentrations of iron. Different types of magnetic ions have different relaxivity. The definition of the relaxivity is given by formula: $1 / \mathrm{T}=\mathrm{rC}$, where $\mathrm{r}$ - relaxivity, $\mathrm{T}$ - relaxation time and $\mathrm{C}$ - concentration of the compound.

The final relaxivity of biological tissues depends on the relaxivity of these ions and on their concentrations. In general all magnetic materials present in biological tissues reduce $\mathrm{T} 1$ and $\mathrm{T} 2$ relaxation times, however $\mathrm{T} 1$ and $\mathrm{T} 2$ depend also on the chemical environment of the magnetic species [10].

Aggregates of magnetic particles isolated from the water by a protein shell are involved in dephasing the magnetic spin of diffusing protons. This mechanism is called the outer sphere mechanism and reduces the T2 relaxation time. Ferritin and hemosiderin act by this mechanism [9]. On the other hand it should be noticed that there are other factors which may also change the relaxation time T2 [12].

The very good linear correlation between the concentration of iron assessed by MS in control and pathological samples and $\mathrm{R} 1=1 / \mathrm{T} 1$, where $\mathrm{T} 1$ is the longitudinal relaxation time in the same structures, confirms a known linear dependence between R1 and the concentration of iron [13]. These results confirm the results of our MS study in which no increase of the total iron concentration in parkinsonian SN compared to control was found [14]. They are also in agreement with our finding for an increase of iron concentration in PSP both in SN and GP [5].

Assessing the dependence of $1 / \mathrm{T} 2=\mathrm{R} 2$ on the concentration of iron, the linear correlation was found only for control samples and GP from PSP. In the figure showing the correlation between R2 and the concentration of iron, the values for samples of SN in PD and SN in 


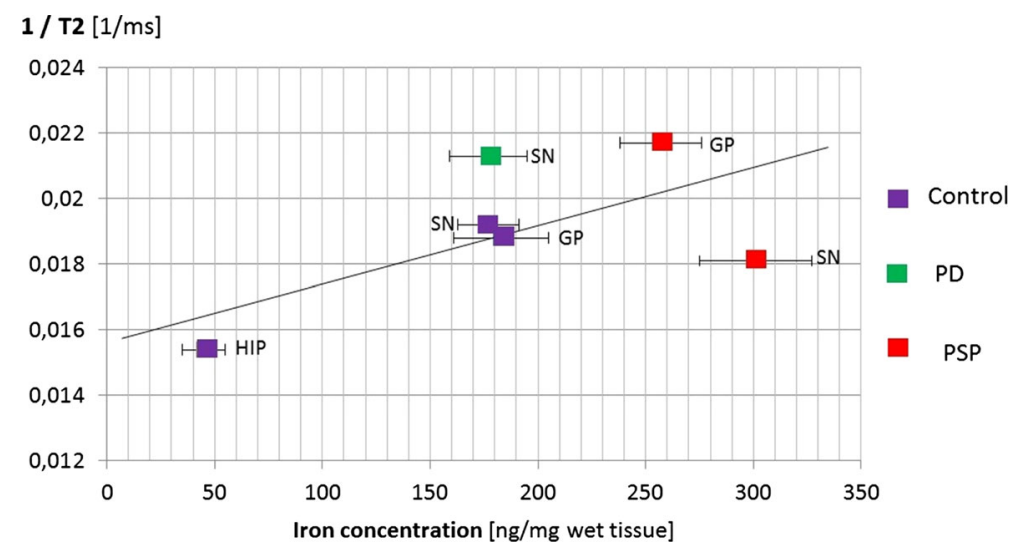

Fig. 5 1/T2 relaxation rate vs. concentration of iron in control (violet), Parkinson's disease (green) and atypical parkinsonism (red). The coefficient of correlation for a linear dependence taking into account all data is only 0.569

PSP defer from this linearity in opposite directions. SN is the structure in which both PD and PSP are involved. Differences of R2 in PSP and PD SNs may be due to many causes. PSP represent a different type of pathology than PD as defined by proteins involved in the process. In PSP the main pathological findings in the affected areas of the brain are aggregates of misfolded protein tau, while in PD the aggregates are formed by a different misfolded protein $-\alpha$-synuclein. It is not known how these proteins may affect relaxation times. T2 relaxation times may depend not only on the concentration of iron but may also be related to the different structure of proteins in the tissues [10]. The different behavior of T2 in PD and PSP may thus be related to different mechanisms of neurodegeneration in these diseases.

Open Access This article is distributed under the terms of the Creative Commons Attribution 4.0 International License (http://creativecommons.org/licenses/by/4.0/), which permits unrestricted use, distribution, and reproduction in any medium, provided you give appropriate credit to the original author(s) and the source, provide a link to the Creative Commons license, and indicate if changes were made.

\section{References}

1. Elbaz, A., Moisan, F.: Update in the epidemiology of Parkinson's disease. Curr. Opin. Neurol. 21, 454460 (2008)

2. Fahn, S., Cohen, G.: The oxidant stress hypothesis in Parkinson's disease: Evidence supporting it. Ann. Neurol. 32, 804-812 (1992)

3. Galazka-Friedman, J., Friedman, A., Bauminger, E.R.: Iron in the brain. Hyperfine Interact. 189, 31-37 (2009)

4. Friedman, A., Galazka-Friedman, J.: The history of the research of iron in parkinsonian substantia nigra. J. Neural. Transm. 119, 1507-1510 (2012)

5. Galazka-Friedman, J., Bauminger, E.R., Szlachta, K., Schweitzer, K., Wszolek, Z., Dickson, D., Friedman, A.: Mössbauer studies of pathological brain tissues affected by PSP disease. Acta Phys. Pol. 115, 431-433 (2009)

6. Dexter, D.T., Carayon, A., Javoy-Agid, F., Agid, Y., Wells, F.R., Daniel, S.E., Lees, A.J., Jenner, P., Marsden, C.D.: Alterations in the levels of iron, ferritin and other trace metals in Parkinson's disease and other neurodegenerative diseases affecting the basal ganglia. Brain 114, 1953-75 (1991) 
7. Bauminger, E.R., Harrison, P.M., Hechel, D., Nowik, I., Treffry, A.: Mössbauer spectroscopic investigation of structure-function relations in ferritins. Biochim. Biophys. Acta 1118, 48-58 (1991)

8. Litvan, I., Bhatia, K.P., Burn, D.J., Goetz, C.G., Lang, A.E., McKeith, I., Quinn, N., Sethi, K.D., Shults, C., Wenning, G.K.: Movement disorders society scientific issues committee report: SIC task force appraisal of clinical diagnostic criteria for Parkinsonian disorders. Mov. Disord. 18, 467-486 (2003)

9. Brooks, R.A., Vymazal, J., Galdfarb, R.B., Bulte, J.W.M., Aisen, P.: Relaxometry and magnetometry of ferritin. Magn. Reson. Med. 40, 227-235 (1998)

10. Schenck, J.F.: Magnetic resonance imaging of brain iron. J. Neurol. Sci. 207, 99-102 (2003)

11. Haacke, E.M., Cheng, N.Y., House, M.J., Liu, Q., Neelavalli, J., Ogg, R.J., Khan, A., Ayaz, M., Kirsch, W., Obenaus, A.: Imaging iron stores in the brain using magnetic resonance imaging. Magn. Reson. Imaging 23, 1-25 (2005)

12. Deoni, S.C.L.: Quantitative relaxometry of the brain. Top. Magn. Reson. Imaging 21, 101-113 (2010)

13. Langkammer, C.H., Krebs, N., Goessler, W., Scheurer, E., Ebner, F., Yen, K., Fazekas, F., Ropele, S.: Quantitative MR imaging and brain iron: A postmortem validation study. Radiology 257, 455-462 (2010)

14. Galazka-Friedman, J., Bauminger, E.R., Friedman, A., Nishida, T.: Iron in neurodegeneration. In: Sharma, V.K., Klingelhöfer, G. (eds.) Mössbauer Spectroscopy- Applications in Chemistry, Biology and Nanotechnology. Wiley, Hoboken (2013) 